\title{
Diacronie
}

Studi di Storia Contemporanea

$N^{\circ} 18,2 \mid 2014$

Le esposizioni: propaganda e costruzione identitaria

\section{Bajo el signo de la esvástica. La Exposición de Arquitectura Moderna alemana en España (1942)}

\section{Francesc Vilanova i Vila-Abadal}

\section{(2) OpenEdition}

\section{Edición electrónica}

URL: http://journals.openedition.org/diacronie/1521

DOI: 10.4000/diacronie. 1521

ISSN: 2038-0925

\section{Editor}

Association culturelle Diacronie

\section{Referencia electrónica}

Francesc Vilanova i Vila-Abadal, « Bajo el signo de la esvástica. La Exposición de Arquitectura Moderna alemana en España (1942) », Diacronie [En línea], № 18, 2 | 2014, documento 15, Puesto en línea el 01 junio 2014, consultado el 19 abril 2019. URL : http://journals.openedition.org/ diacronie/1521; DOI : 10.4000/diacronie.1521 


\section{Diacronie}

\section{Bajo el signo de la esvástica. La Exposición de Arquitectura Moderna alemana en España}

(1942)

Francesc VILANOVA i VILA-ABADAL *

Entre mayo y octubre de 1942, llegó a España la Exposición de Arquitectura Moderna Alemana, la magna exhibición comisariada por Albert Speer y sus colaboradores, que fue presentada en toda Europa como el catálogo más completa de las realizaciones arquitectónicas y urbanísticas de la nueva Alemania. Tras su paso por Madrid, donde la exposición fue inaugurada por el dictador español, general Francisco Franco, la exposición recaló en Barcelona, donde se convirtió en un acontecimiento social y fue visitada por más de 30.000 personas. El impacto de sus contenidos se sumó a la enorme fascinación que la Alemania nazi despertaba en los círculos intelectuales y políticos de la ciudad. Este artículo recoge las reacciones que provocó la Exposición en la Barcelona de otoño de 1942.

En memoria de Jordi Vilanova Bosch, que visitó la Exposició en Barcelona

A través del contraluz de rubios rapaces, firmes en sus camisas siena natural, he saludado los modelos y las estampas de edificios, cuya gestación tanto me preocupará antaño y cuya realidad magnífica, siquiera en su transunto a escala reducida, nos lleva hoy a asomar la cabeza al mirador del mundo travertínico y mayestático, cilópeo e imponente de la arquitectura bajo el signo de la svástica (BASSEGODA, Buenaventura, «La nueva arquitectura alemana», en Destino. Política de Unidad, 276, 31 octubre 1942) 


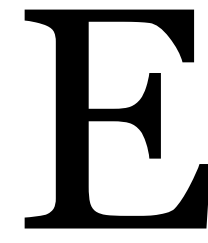
ntre los años 1939 y 1944, las ciudades de Barcelona y Madrid vivieron vivió una intensa etapa de excelentes relaciones y presencia constante de la Alemania nazi en sus calles, teatros, centros oficiales, salas de concierto, etc. En Barcelona, las autoridades franquistas del lugar - desde el Capitán General, máxima autoridad militar de la región, hasta los presidentes de Academias y centros culturales, el Rector de la Universidad de Barcelona, pasando por los máximos responsables políticos del ayuntamiento, el gobernador civil y jefe provincial de Falange, etc. - dieron la bienvenida, una y otra vez, a todo tipo de delegaciones provenientes del III Reich, tanto políticas como culturales, académicas y deportivas, militares y juveniles. ${ }^{1}$ Proliferaban las visitas de los coros de las Juventudes Hitlerianas, las conferencias académicas de Lothar Altmeyer², E.W. Brader3, el hispanista y viejo conocido en los ambientes académicos barceloneses Karl Vossler ${ }^{4}$, o la muy notable por ser quien era el personaje y la fecha de la conferencia, 6 de junio de 1944, en pleno desembarco aliado en Normandia- del jurista Carl Schmitt 5 . Pero no hay que olvidar

1 Una primera aproximación a este fenómeno de la posguerra barcelonesa, en: PÉREZVALLVERDÚ, Eulàlia (dir.), Barcelona en postguerra, 1939-1945, Barcelona, Efadós, 2014.

2 Lothar Altmeyer dio una conferencia, el 31 de mayo de 1944, acerca de las «Características esenciales del paisaje alemán», que, según se apuntaba en el programa de mao, «encuadra la fisonomía propia de Alemania en la gran unidad europea y procura esclarecer, al mismo tiempo, las fuerzas que el ambiente geográfico ofrecen al hombre». Los contenidos de la conferencia, a tenor de las explicaciones previas, remitían a las prácticas de la Geopolítica, muy de moda en aquellos años, y que desde Alemania había llegado a círculos académicos italianos, españoles, etc., simpatizantes de esta vía pseudocientífica. Para el caso español, cfr. VILANOVA, Francesc, España en el nuevo orden europeo. Algunas lecturas franquistas de posguerra, en MORENO CANTANO, Antonio César (coord.), El ocaso de la verdad. Propaganda y prensa exterior en la España franquista (1936-1945), Gijón, Ediciones Trea, 2011, pp. 215-250.

3 Catedrático en la Universidad de Berlín, dio dos conferencias: «La lucha contra el polvo en las fábricas» (5 de noviembre de 1940) y la más interesante, y significativa, «Fines y métodos de la formación y selección profesional del obrero alemán» (6 de noviembre de 1940).

4 Su visita a la ciudad, en marzo de 1944, estuvo rodeada de los máximos honores y fue recibido por las primeras autoridades civiles, militares y académicas franquistas del momento. Ofreció dos conferencias: «La influencia europea de San Isidoro», en la universidad; y «Las culturas neolíticas y el espíritu germánico», en el Ateneo Barcelonés. Según la prensa (La Vanguardia Española, 17 marzo 1944), en su segunda conferencia habría afirmado: «...en el gran diálogo latinorrománico las voces hispánicas son las que suenan a los germanos con acentos más simpáticos y familiares y que gran parte de la riqueza psíquica germánica se generó en el papel de España como mediadora entre las civilizaciones mediterráneas y atlánticas y, por último, y en relación con la Europa actual, dijo que el bolcheviquismo no puede colaborar en la magna tarea de la cultura europea porque carece del sentido fundamental de la solidaridad».

5 El jurista Carl Schmitt había sido invitado por el Colegio de Abogados de Barcelona, para dar una conferencia sobre «La situación actual de la Ciencia del Derecho en Europa»: «El doctor Schmitt trató de la situación actual de la Ciencia del Derecho en Europa, según un derecho europeo común, que solamente existiría en cuanto los pueblos europeos en conjunto hubiesen partido del Derecho Romano. Los sistemas jurídicos en vigor, que habían sido ya amenazados anteriormente por el positivismo y que habían continuado en lucha con la técnica en progreso, sufren hoy también una profunda crisis, lo que dejaría de tener su expresión en la actual contienda. El profesor Schmitt pasó a considerar seguidamente la personalidad del gran hombre de ciencia jurídica alemán F.K. von Savigny, fundador de la histórica Escuela Jurídica, cuyos 
otras presencias, de un cariz mucho más político -e, incluso, pintoresco (para no llamarlo directamente esotérico)-, como la del Reichsführer Heinrich Himmler, en octubre de 1940, recibido en la ciudad «como uno de los más egregios forjadores de la nueva Alemania [...] quien tanto hizo, con un ardiente patriotismo, que ha de merecer aplauso de todos los corazones nobles, que sientan su respectivo patriotismo, para sacar a su país de la humillación del ludribio y de la ruina a que le había condenado el sanedrín de Versalles» 6 .

Durante los años centrales de la segunda guerra mundial, la Barcelona franquista fue un escenario perfecto para visualizar la epopeya nazi, primero en Alemania, y después en su proyección continental. El III Reich se erigía como un ejemplo de renacimiento político, cultural, militar y económico; el resurgimiento de un histórico poder europeo, que estuvo a punto de sucumbir a los embates del «sanedrín de Versalles» y de las diversas conspiraciones judeo-bolcheviques de los años posteriores a la primera guerra mundial. La Alemania nazi producía fascinación en Barcelona; esta era la palabra: fascinación; quizá también serviría deslumbramiento. Manuel Penella de Silva, corresponsal de prensa falangista en Berlín, lo intentó expresar con cierto tono lírico: «iLa noche! iLa noche! He aquí el tema extraño y virgen de la Gran Alemania. Duerme el pueblo ario, el de los hijos de la luz, mientras su Führer, bajo la luna que saca platas de aquellas montañas, atento al bien de su pueblo, cosecha inspiración en las profundidades de la noche. ¿Y qué negará ella a sus fieles enamorados?»7. En la proyección exterior de la Alemania nazi, el fascismo español se sentía reconocido, encontraba un referente en el nuevo horizonte europeo. Al menos, esto se desprendía de lo escrito por Manuel Aznar, uno de los periodistas más influyentes de la posguerra española y hombre muy cercano al dictador, Francisco Franco: «[...] es España la que en la actitud de Alemania ha reconocido, reconoce y proclama que el mundo germánico de Hitler está sirviendo profundamente a los más altos y eternos fines del espíritu. Del triunfo de esos fines va a nacer el nuevo orden de Europa» ${ }^{8}$. Prescindiendo -porque se

trabajos siguen teniendo aún hoy importancia para Europa entera» (La Vanguardia Española, 8 julio 1944).

6 «Himmler o la paz interior de Alemania», en La Vanguardia Española, 23 octubre 1940. Lo de esotérico se refiere a su visita a la montaña y monasterio benedictino de Montserrat, según parece para encontrar pistas de la hipotética localización del Santo Graal (en la literatura esotérica germánica, Montserrat podría ser la mítica montaña Montsalvat, donde habría sido escondido el codiciado objeto sagrado).

7 PENELLA DE SILVA, Manuel, «El trabajo del Führer. La tarea en la noche», en Destino. Política de Unidad, 185, 1 febrero 1941. Periodista valenciano, fue jefe de Falange Española y Tradicionalista y de las JONS - el partido fascista español - en Baden, Palatinado y Saar, y corresponsal de Diario de Barcelona, el semanario Destino. Política de Unidad y El Alcázar (periódico de Madrid), en Berlín en los tres primeros años de la guerra.

8 AZNAR, Manuel, «Política de España en Europa, y II», en Solidaridad Nacional, 14 julio 1940. 
prescindió hasta más allá de 1944 - de ciertos aspectos incómodos que provocaba el régimen nazi a la dictadura nacional-católica española - el neopaganismo, el discurso eugenésico, las prácticas eutanásicas, el antisemitismo racista (pero no el de origen católico; aquí había bastantes franquistas dispuestos a manifestarse contra los judíos) , todo lo que venía de Alemania - jóvenes, libros, propaganda, deportistas, dirigentes del partido nacional-socialista, etc. - era digno de ser admirado y proyectado mediante la prensa y los noticiarios oficiales. Eran grandes acontecimientos en una posguerra española, y barcelonesa, dura, miserable y sin ningún aliciente más allá de la pura supervivencia.

\section{La exhibición del nuevo orden: la arquitectura y su arquitecto principal}

Si el cine fue una de las vías más usadas para impactar en los ciudadanos barceloneses, con la esperanza que cayeran rendidos ante la pujante realidad alemana ${ }^{9}$, la organización y exhibición de todo tipo de exposiciones -artesanía, dibujo, prensa, trabajos escolares en el Colegio Alemán, etc. ${ }^{10}$ - era otra posibilidad de penetración de la propaganda nazi y de exaltación de su poderío. En este contexto, sin duda, la exposición más importante fue la de arquitectura moderna alemana, la nueva arquitectura del III Reich.

Que la arquitectura - y el urbanismo - era uno de los aspectos esenciales de la construcción del nuevo orden nazi, fuese en Alemania o en los territorios conquistados y ocupados, era algo bastante bien conocido desde hacía algunos años ${ }^{11}$. La afición del dictador alemán por estas cuestiones era legendaria y su intervención directa en este campo de actividades era bien conocida. Por ejemplo, un año antes de la exposición y en pleno proceso de embelesamiento ante la epopeya nazi en el continente - concluídas las victorias en el oeste, incluyendo la estrepitosa caída de Francia, y en espera de saber

\footnotetext{
9. Por ejemplo, el estreno de la película de las Juventudes Hitlerianas, El flecha Qex, en el cine Savoy el 16 de junio de 1939. Un mes más tarde se estrenaba, en el mismo cine, Olimpiada, de Leni Riefensthal. El 27 de mayo de 1941, en el cine Astoria, se estrenaba La victoria en el Oeste. 10. La Exposición del Libro Alemán tuvo lugar en el paranimfo de la Universidad el 15 de febrero de 1941. En abril del mismo año, se inauguró otra dedicada a la prensa. Y no hay que olvidar las actividades públicas del Instituto de Cultura Alemán, o las del Colegio Alemán.

11. Dos días después de la inauguración de la Exposición de Arquitectura Moderna alemana en Barcelona, se había previsto el inicio del Segundo Congreso de la Federación de Urbanismo y de la Vivienda española, también en la ciudad. Para mayor coincidencia, las sesiones del congreso se celebraban en el mismo lugar, el llamado Palacio de Arte Moderno, que la exposición alemana (Solidaridad Nacional, 21 octubre 1942). A imitación del III Reich, la dictadura franquista también quería presumir del binomio arquitectura-urbanismo. Como veremos más adelante, en Madrid ocurrió algo similar.
} 
qué ocurriría con la Unión Soviética -, uno de los analistas más importantes de la Barcelona franquista, el católico Manuel Brunet, se rendía, admirado, al genio constructor alemán - y, también, al italiano: «¿No es una paradoja que los dos propulsores más grandes que la arquitectura ha tenido en nuestra época, Hitler y Mussolini, deban servirse de esta arma [la aviación]contra la arquitectura? No dudéis de que a esos dos hombres la acción destructora de los aviones de bombardeo les horroriza. Pero el atraso moral de la humanidad no les permite hacer otro uso de esta nueva arma. [...] Suponer que cada uno de esos dos hombres encarna un genio de la destrucción sería grotesco. Ambos han creado o impulsado la construcción de grandes monumentos ${ }^{12}$. Un comentario de esta categoría, proveniente de un comentarista solvente y buen conocedor del mundo que le rodeaba - como era el caso de Manuel Brunet -, sólo podía explicarse en la España de posguerra por dos motivos: la fascinación que despertaba la epopeya nazi en aquellas fechas; y la admiración de las derechas europeas - y del franquismo español, en particular - por la figura de Adolf Hitler, quien, a pesar de cierta vulgaridad personal, había ganado la batalla de la opinión y de la imagen ante este mundo conservador europeo, con quien compartía su odio al comunismo y el desprecio por las democracias.

La imagen de Hitler como gran constructor, en definitiva como gran arquitecto, sin serlo, que evocaba Manuel Brunet en febrero de 1941, no estaba muy lejos de la que proyectó el cónsul alemán en Barcelona, doctor Jaeger, en su parlamento de inauguración de la exposición, casi dos años más tarde: «Adolfo Hitler [...], cuya voluntad se concentra en forma tan intensiva sobre la construcción de obras de paz y que en su discurso cultural del Día del Partido, en 1935, manifestó su profunda convicción de que "ningún pueblo vive más allá de los documentos de su cultura", había deseado de todo corazón la paz para su pueblo para poder dar forma a estas monumentales construcciones de arte, ya que solamente la paz garantiza la libre continuación y feliz terminación de tales obras...» ${ }^{13}$. Ciertamente, Adolf Hitler era considerado el arquitecto de Alemania - con permiso de su arquitecto, este sí auténtico, de confianza, Albert Speer -, pero la nueva arquitectura alemana - y el urbanismo - no era solamente la obsesión de un megalómano sin control.

Al contrario; los gigantescos proyectos para convertir Berlín en el centro del nuevo poder alemán en Europa - la futura capital, rebautizada con el nombre de Germania -,

12 ROMANO [BRUNET, Manuel], «La guerra y la arquitectura», en Destino. Política de Unidad, 186, 8 febrero 1941.

13 «La Exposición de Arquitectura Moderna alemana. Fue inaugurada ayer solemnemente, presidiendo el acto el Embajador de Alemania en España y nuestras primeras autoridades», en Diario de Barcelona, 21 octubre 1942. 
se correspondían «amb la nova filosofia d'expansionisme en la política exterior» ${ }^{14}$ nazi. En este sentido, no había nada de gratuito o dejado al azar en el interés nazi por la arquitectura; por el contrario, Wolfgang Schächer escribe, sin dudarlo un instante, que «l'ús, per part dels nazis, de l'“arquitectura de la remodelació” com a instrument de poder es lligava indissolublement i va portar inevitablement a la guerra. En la síntesi de l'arquitectura, les armes i la guerra, conjuntament amb la joia sagnant de la conquesta mundial i "la raça superior", sorgeix una estètica de l'horror» 15.

Para desarrollar esta apoteosis arquitectónica y urbanística - que, «pedra per pedra, carrer per carrer, [...] evocava les perspectives imperials sobre la futura hegemonia mundial»16 -, Hitler escogió un arquitecto «sediento de cargos» $\mathrm{y}$ «nacionalsocialista entusiasta»17, en la persona de Albert Speer, pràcticament su arquitecto particular. El 30 de enero de 1933, Speer fue nombrado inspector general de Obras Públicas, un cargo equivalente al de ministro, responsable sólo ante Hitler. Desde este momento, y hasta su designación como ministro de Armamento, «tota activitat constructora que no es relacionés amb els plans de Speer, especialment en l'esfera privada o comercial, es podia suspendre "per ordre del Führer", per tal que els materials i la mà d'obra quedessin lliures» para todo tipo de reformas arquitectónicas $o$ urbanísticas consideradas prioritarias o de interés del Estado ${ }^{18}$.

Desde este momento, y hasta el hundimiento del III Reich, Albert Speer se convirtió en un personaje fundamental en la trama del poder nazi, más allá de la maquinaria de guerra, exterminio, represión y ocupación del continente. Fue un colaborador necesario y entusiasta en la construcción - literal y metafórica - de la Alemania nazi y autor de

${ }^{14}$ SCHÄCHER, Wolfgang, De Berlín a «Germania». Arquitectura i planificació urbana, en Art $i$ poder. L'Europa dels dictadors, 1930-1945, Barcelona, CCCB-Diputació de Barcelona, 1996, p. 326. En castellano: «con la nueva filosofía de expansionismo en la política exterior».

15 Ídem, p. 329. En castellano: «la utilización, por parte de los nazis, de la "arquitectura de la remodelación" como instrumento de poder se vinculaba indisolublemente y llevó inevitablemente a la guerra. En la síntesis de la arquitectura, las armas y la guerra, junto a la alegría sangrienta de la conquista mundial y "la raza superior", surge una estética del horror».

16 Ibídem, p. 327. En castellano: «piedra a piedra, calle por calle, [...] evocaba las perspectivas imperiales sobre la futura hegemonía mundial».

${ }_{17}$ OVERY, Richard, Interrogatorios. El III Reich en el banquillo, Barcelona, Tusquets, 2003, p. 157. Más adelante, Richard Overy se muestra implacable con el personaje: «Dio muestras de una notable indiferencia moral en el curso de estas conversaciones [con los interrogadores aliados en Nuremberg]. No explicaba su oposición al traslado de mano de obra judía alegando razones morales contra el antisemitismo, sino razones prácticas. [...] No condenaba el empleo de mano de obra extranjera, sino que lamentaba que su eficacia fuera mucho menor que la alemana. La culpabilidad de Speer era innegable, como lo es la del hombre que adquiere mercancía robada...». Ibidem, p. 161.

${ }^{18}$ SCHÄCHER, Wolfgang, op. cit., p. 362. En castellano: «toda actividad constructora que no se relacionase con los planes de Speer, especialmente en la esfera privada o comercial, se podía suspender "por orden del Führer", con el fin de que los materiales y la mano de obra quedasen disponibles...». 
algunas obras, como el Zeppelinfeld, que evocaban uno de los «racons més pertorbadors de l'inexplicable» ${ }^{19}$.

\section{Mayo de 1942: la Exposición, en Madrid}

En mayo de 1942, la espectacular exposición alemana recaló en Madrid, donde sería inaugurada por el dictador español y, tan importante como esto, se sumaría a la apertura de una exposición paralela de arquitectura española, organizada deprisa y corriendo «como un deber de elemental cortesía» y expresión de «cortés y cordial camaradería entre dos entidades profesionales constantemente relacionadas con una directa amistad»20. ¿Qué iban a ver el Caudillo y su séquito, de la propuesta de sus amigos y aliados alemanes? Según la descripción del periódico monárquico-franquista madrileño $A B C$, los contenidos eran espectaculares: «Con una extraordinaria riqueza de material se exhiben modelos de los edificios representativos del movimiento nacionalsocialista y, entre ellos, los que constituyen la Plaza Real de Munich, sede del nazismo, y la nueva Cancellería del Reich, que son obras gigantescas de ingeniería; la arquitectura militar donde la intervención directa de la arquitectura arranca en el edificio del Alto Mando del Ejército; la ciudad Herman Goering, representativa de la población moderna en Alemania; el gran Stadio de Nuremberg; el Palacio de Congresos de la misma ciudad; la gran plaza Redonda de Berlín, que constituye uno de los lugares de reforma a fondo de la capital, etc., nos muestran la enorme capacidad constructiva del pueblo alemán y la grandiosidad que sabe imprimir a sus obras». La cumbre de la exposición era el proyecto de reforma de Berlín -la futura megalópolis Germania-, «a cargo de Speer, de una magnificiencia y de un sentido moderno, en bellísima alianza, que causa extraordinaria admiración».

La crónica, sin embargo, no terminaba aquí; había algo más: «Se puede decir, sin exageración, que desde que se penetra en esta Exposición hasta que se sale de ella, un interés creciente domina el espíritu. La moderna arquitectura alemana no representa en modo alguno una ruptura con la tradición cultural alemana y con la evolución artística europea, sino que es más bien una representación grandiosa, en nuestros días, de los valores perennes de aquéllas. Es, al mismo tiempo, una demostración de la potencia creadora de la nueva Alemania y un testimonio de su sentido espiritual. El

19. BENTON, Tim, Parlar sense adjectius. L'arquitectura al servei del totalitarisme, en Art $i$ poder, op. cit., p. 36.

${ }^{20}$. «Hoy en el Retiro. La gran Exposición de Arquitectura Moderna alemana y la de trabajos de la Dirección General de Arquitectura de España», en $A B C, 6$ mayo 1942. 
Führer ha sabido rodearse de especialistas eminentes para llevar a cabo su alta concepción arquitectónica» ${ }^{21}$.

¿Qué podían ofrecer los rendidos y fascinados admiradores españoles de la Alemania nazi? Muy poca cosa y notablemente menos espectacular: «el mejoramiento de las viviendas humildes», "las mejoras en los poblados de pesqueros y en los suburbios y zonas superpobladas» y algunas muestras de la reconstrucción de Santander -víctima de un gran incendio tiempo atrás-, la urbanización de la plaza del Pilar, en Zaragoza, la ampliación del Museo del Prado y poca cosa más. La joya de la exposición española, «máxima expresión de la arquitectura nacional», era «el monumento que, por expresa indicación del Caudillo, se eleva a los héroes de nuestra guerra de liberación cerca de San Lorenzo del Escorial, en el Valle de los Caídos».

¿Podía competir el Valle de los Caídos con la llamada Sala de las Asambleas, de Albert Speer, considerada un «un emblema de la cobejada hegemonia mundial» 22 ? Sin duda alguna, no. El intento de competir que suponía la exhibición de proyectos arquitectónicos y urbanísticos españoles, en paralelo a la muestra alemana, estaba condenado al fracaso desde un principio. La exposición nazi estaba pensada para proyectar, desde Alemania hacia el conjunto del continente, la obra hecha y la futura; Alemania - o Berlín, como su centro - ya no se limitaba a ser un punto en el mapa, un lugar concreto, sino que actuaba como metáfora de lo que sería la nueva Europa urbana, sometida al dominio y a las directrices de los nazis. Las reformas de Berlín no estaban pensadas para embellecer y modernizar la capital alemana; eran la expresión real de la futura Germania, la nueva capital de Europa. Ciertamente, parte de la muestra expositiva se limitaba a construcciones rurales, pequeños proyectos locales; sin embargo, solamente eran complementos del núcleo central. Enfrente, o paralelamente, el franquismo sólo podía ofrecer un monumento funerario gigantesco, levantado por presos político, de un lamentable gusto estético, arquitectónicamente retrógado - en eso coincidía con parte del «nuevo estilo alemán», ideológicamente y estéticamente antimoderno - y dominado por el discurso nacional-católico vigente en aquellos años. De hecho, el bajo nivel de la exposición española se correspondía con la talla intelectual de los principales jerifaltes franquistas.

Naturalmente, la prensa española - mediatizada y controlada muy de cerca por el poder - se esforzó para poner en un mismo plano de igualdad las realizaciones

21. En la misma línea va la descripción del «Contenido de la Exposición de Arquitectura Moderna alemana», en $A B C, 7$ mayo 1942, que termina de forma apoteósica: «El conjunto de esta Exposición es tan artístico y tan sugestivo que difícilmente podría ser superado».

22. SCHÄCHER, Wolfgang, op. cit, p. 329. En castellano: «un emblema de la codiciada hegemonía mundial». 
alemanas y españolas. Detrás de cada gran obra arquitectónica o urbanística, estaban los genios creadores de Hitler y Franco. Después venían las reflexiones más profundas: «La arquitectura es base firme de expresión de una cultura. Ese amor a las viejas ruinas legadas por los pueblos clásicos no es otra cosa sino el reflejo de cómo consideramos la civilización que supo y pudo realizar tales obras. Hoy, Alemania e Italia, por ejemplo, conceden enorme importancia a la arquitectura que constituye tema preferente y dominante de sus actividades, incluso en los tremendos momentos actuales. En España, también. El Caudillo, desde que empuñó las riendas del Gobierno, se preocupó de estos problemas, y en la misma guerra de liberación dedicóles atención preferentísima. [...] Hay en todo ello, lo mismo en Alemania e Italia que en España, una ambición que surge de la misma concepción política de los tres Estados...»23. Era una muestra de sinceridad que iba mucho más allá de las indicaciones que hubiese hecho llegar la censura franquista a los medios. La arquitectura como proyecto político, como herramienta ideológica de construcción política, hermanaba en una «misma concepción política» las tres supuestas grandes potencias fascistas del continente. Para un régimen como el franquista - que, a partir de 1944, se apresuró a desmentir que tuviese similitudes con el nazismo alemán o con el fascismo italiano -, presentarse, en mayo de 1942, en un plano de igualdad con el pujante nazismo, ya era un triunfo.

El 6 de mayo se llevó a cabo la inauguración. Por parte alemana, la representación era muy notable. En ausencia de Albert Speer, comisario oficial de la exposición, la delegación estaba encabezada por el embajador en Madrid, Von Stohrer. Representaban a Speer el alcalde de Nuremberg, Willy Liebel; Wilhelm Kreis, consejero general de Arquitectura; Rudolf Wolters, comisario de Exposiciones; Gerhard Frank, vicepresidente de la Inspección General de Arquitectura; Renner, director de la exposición y Brichbach, consejero ministerial y jefe de la sección de Artes Plásticas en el ministerio de Propaganda alemán.

A las doce y diez de la mañana llegaba el dictador español para presidir la inauguración. Después de los saludos, la revista militar, etc., el general Franco empezó el recorrido, acompañado de la numerosa delegación alemana: «El embajador Von Stohrer, y el profesor doctor Wilhelm Kreis, fueron explicando minuciosamente al Caudillo cada una de las maquetas expuestas y respondiendo a las preguntas que les iba formulando en cada una de las salas de la magnífica Exposición, que además están ilustradas con espléndidas y bellísimas fotografías de esta obra ingente de arquitectura. Fijó su atención el Jefe del Estado en un busto suyo, obra en yeso pintado en bronce, de un verdadero acierto y del que es autor el arquitecto alemán Blum Martin, que realiza

23. $A B C, 7$ mayo 1942. 
intercambio de estudios en Madrid. El Caudillo pidió que le fuera presentado, cosa que hizo el arquitecto de Stuttgart Sr. Jansen. El Caudillo le felicitó muy efusivamente, así como al embajador de Alemania y a los arquitectos y personalidades de aquel país por la magnificiencia de la obra que ofrecen al conocimiento de los españoles y que pone de relieve la importancia que Alemania concede a la intervención directa de la arquitectura en todo género de construcciones, sean civiles, sean militares» ${ }^{24}$. Leyendo entre líneas, parece evidente que el Caudillo no solamente tenía conocimientos muy limitados sobre arquitectura y urbanismo, sino que además su interés por la materia no era muy notable. En este aspecto, y a pesar de los esfuerzos de la prensa franquista y los medios oficiales, no podía competir con la fama de constructores y urbanistas de sus colegas fascista y nazi. De los tres dictadores, sin duda alguna el general Franco era el último en la cola de la galería de grandes constructores de la nueva Europa.

\section{Un libro para la Exposición}

Las dos exposiciones, en Madrid y Barcelona, llegaron acompañadas de un libro que haría las funciones de catálogo. Preparador por el mismísimo Albert Speer y con un extenso prólogo de Rudolf Wolters, La nueva arquitectura alemana/Neue deutsche baukunst era un un libro bilingüe alemán-español, publicado por Volk und Reich Verlag, de Berlín, en 1941, que quería mostrar, con la inclusión de numerosas láminas y fotografías, el trabajo realizado «en los ocho años transcurridos desde la toma del poder por Adolfo Hitler» en el campo de la arquitectura y el urbanismo o, como escribía Albert Speer en la presentación, «el nuevo aspecto de las ciudades alemanas».

El libro impresionaba, tanto por la calidad de la edición como por el contenido gráfico - un despliegue notable de láminas de obras construídas, otras en vías de realización y proyectos por empezar - y las extensas explicaciones de Rudolf Wolters. El colaborador de Albert Speer presentaba un auténtico tratado sobre la relación entre la arquitectura y la política y, yendo más lejos, el lugar central que la arquitectura tendría en la Alemania nazi, pasadas las turbulencias de la guerra:

La revolución de 1933 es para Alemania una transformación en todos los terrenos de la vida nacional. Paralelamente con la renovación política y social va el resurgimiento en el aspecto cultural. El Führer de Alemania, Adolf Hitler, se aplica él mismo a esta tarea. Su preferencia va a la arquitectura.

24 Ibidem. 
Los fines que se persiguen son orden y claridad. Se pone mano a la obra radicalmente. Por de pronto no se trata del «estilo», de la forma. Se trata, más bien, de lo fundamental: el nuevo arte arquitectónico debe emanar de la nueva vida. En construcciones de piedra debe simbolizar al pueblo y a su tiempo. Por eso, de la misma tarea, del propio contenido, irá sacando la propia forma.

El espíritu arquitectónico de la Alemania de hoy se diferencia del de grandes épocas pasadas en algo esencial. Ese espíritu abarca más que nunca todo el espacio vital y va dando conscientemente forma al todo. La planificación (Raumordnung) no sólo es un concepto de nuestro tiempo sino que es característico y exclusivo suyo. Todo lo que se construye en grande se ordena con arreglo al todo, se supedita a la planificación. Las ciudades y el paisaje cobran un sentido especial dentro del todo. Así, Berlín será arquitectónicamente también la capital del Reich, Nuremberg, la ciudad de los Congresos del Partido, Munich, la capital del Movimiento, Hamburgo, la ciudad del comercio exterior, Graz, la del levantamiento nacional, etc. Las capitales de las provincias cobrarán un sentido que responda a su especial situación e importancia dentro del Reich y con referencia al todo. Los «Ordensburgos» y las Escuelas políticas se distribuirán por el Este y por el Oeste, por el Centro y por las fronteras, constituyendo nuevos centros y simbolizando la idea del Reich y la comunidad del pueblo25.

Después de esta declaración de principios, Rudolf Wolters presentaba detalladamente las principales obras dignas de aparecer en el libro y que definían la nueva arquitectura alemana: Munich y su Plaza Real; la Casa del Arte Alemán; el Forum del Movimiento, en Nuremberg; la Nueva Cancillería, en Berlín; etc. Un amplio catálogo de realizaciones y proyectos que solamente podía provocar la admiración de cualquier espectador interesado en la nueva arquitectura alemana o entusiasta de todo aquello - sobretodo en este terreno - que, supuestamente, era «nuevo» en el movimiento nazi.

Sin embargo, no era necesario ser nazi o simpatizar con el nacionalsocialismo para sentirse admirado, fascinado, por las propuestas arquitectónicas presentadas en el libro (y su traslación a las maquetas, fotografías y dibujos de la exposición). Un católico poco sospechoso de simpatías nazis - pero notable germanófilo en aquella coyuntura -, como el analista Manuel Brunet, recibió con entusiasmo la publicación ${ }^{26}$ : un «libro maravilloso, tan bueno como un excelente libro de versos, impreso en suntuoso papel y con grabados magníficos, especialidad muy alemana».

25 WOLTERS, Rudolf, La nueva arquitectura alemana/Neue deutsche baukunst, Volk und Reich Verlag, de Berlín, 1941, p. 10.

26. BRUNET, Manuel, «Arquitectura política», in Destino. Política de Unidad, 278, 14 noviembre 1942. 
Así empezaba su comentario Manuel Brunet, quien no escondía que veía en el libro de Speer y Wolters un ejemplo de «propaganda ideológica», pero de una especie que contenía "verdades rotundas, verdades en piedra». Después seguía una excursión narrativa, muy erudita, por el territorio de las relaciones entre la arquitectura y el poder, desde los griegos hasta Luis XIV, pasando por unos cuantos ejemplos bíblicos. Del extenso recorrido que llevaba a cabo Manuel Brunet, destacaba algun párrafo especialmente significativo:

\begin{abstract}
[...] Un dictador no está obligado a tener sobre la Arquitectura un conjunto de ideas claras como Adolfo Hitler, que nació con vocación de arquitecto. Pero no es inverosímil que a un dictador con menos principios artísticos le endosen un palacio o una serie de edificios estilo Palacio de la Música de Barcelona ${ }^{27}$. Argüir que una política de gran estilo crea un arte de gran estilo, sería peligroso. Los griegos vivieron en un caos político casi perpetuo, y no obstante, crearon varios estilos de los que todavía vivimos. Napoleón tuvo mucha suerte en este aspecto, aunque, de vez en cuando, los hombres de L'Action Française se hayan permitido hablar poco respetuosamente del estilo Imperio, considerando que era un pastiche en comparación con el que usó el Rey Sol. En cambio, la Tercera República francesa y los liberales italianos han tenido mala suerte. Casi todos sus edificios son catastróficos. No es que no sintieran la necesidad de erigir grandes construcciones, pero el estilo de la época no les fue propicio. El ejemplo es el colosal Vittoriale, de Roma...28.
\end{abstract}

Gran conocedor de Roma y del fascismo, Manuel Brunet reivindicaba la arquitectura del fascismo italiano como iniciadora de un movimiento antimodernista -

27. El Palacio de la Música (Palau de la Música Catalana, su nombre històrico hasta 1939, cuando la dictadura franquista prohibió el uso público de la lengua catalana y el cambio de nombres de edificios, instituciones, comercios, calles, etc.) es uno de los máximos exponentes de la arquitectura modernista catalana y europea. Obra del arquitecto Lluís Domènech i Montaner, desde el principio tuvo notables detractores (y defensores fervientes). La cita de este edificio, por parte de Manuel Brunet, se debe entender en el contexto de una campaña de españolización del modernismo catalán, movimiento que, desde sus inicios y en todas sus expresiones (arquitectura, literatura, artes decorativas, etc.), estuvo muy vinculado al catalanismo político. Cfr. CASTELLANOS, Jordi, Postguerra: del «19oo» al modernisme. La reivindicació d'un moviment, en GASSOL BELLET, Olívia (ed.), Postguerra. Reinventant la tradició literària catalana, Lleida, Punctum, 2011, pp. 27-49.

${ }^{28}$. La visión crítica de Manuel Brunet acerca de la arquitectura italiana ya venía de lejos. En otro de sus artículos en Destino. Política de Unidad («En el XX aniversario del fascismo», 227, 7 noviembre 1942), tras señalar que el criterio fundamental para construir «el ensanche» romano fue «que la cúpula del Vaticano no se viera desde ninguna calle, señal inequívoca de que la masonería italiana era tan cerril como la nuestra», iba al núcleo del asunto: «El esfuerzo realizado por el fascismo en materia de obras públicas y urbanismo no tiene rival en ningún país del mundo. Ha hecho más el fascismo en veinte años que la Tercera República francesa desde 1870. Todo esto es innegable...». 
el Palau de la Música Catalana, que citaba anteriormente - y antifuncionalista tomando el Palacio de la Sociedad de las Naciones, en Ginebra, como ejemplo -, en el que se incardinaba la nueva arquitectura moderna alemana de Troost y Speer, que había conseguido «ofrecer un estilo a un régimen».

\section{Barcelona (octubre de 1942): el triunfo de la Exposición}

Con el libro como tarjeta de presentación, y plenamente conscientes de que el acontecimiento tenía una importancia singular - había quedado bien demostrado en Madrid, con la presencia del dictador en la inauguración; pero, para Barcelona, representaba un punto álgido en la presencia alemana en la ciudad -, las autoridades nazis trasladaron la exposición a Barcelona - antes de recalar en la ciudad catalana, y después de Madrid, había viajado a Lisboa -, convencidas, y no se equivocaban, de que sería recibida con todos los honores por parte de los dirigentes políticos y culturales del franquismo local. Los antecedentes eran un aval para ser optimistas: la exposición del libro alemán en la Universidad, en febrero de 1941, había tenido una acogida notable y los actos que la habían acompañado (conferencias académicas, visitas guiadas, etc.) demostraron que la clase política e intelectual dominante era especialmente receptiva a las grandes muestras expositivas, académicas, deportivas, etc., provenientes de la Alemania nazi.

En un contexto especialmente favorable, la Exposición fue instalada en un lugar de alta carga simbólica para la ciudadanía. Todas las crónicas y convocatorias indicaban que la muestra podría verse en el llamado Palacio de Arte Moderno de la Ciudadela -las autoridades franquistas se referían al Parc de la Ciutadella, un amplio recinto ajardinado, levantado sobre la fortaleza militar que dominaba buena parte de la ciudad tras la victoria borbónica en la Guerra de Sucesión de 1714. La denominación oficial franquista del edificio ocultaba una verdad amarga: entre abril de 1931 y enero de 1939, el palacio había acogido el Parlament de Catalunya, la cámara de diputados catalanes, elegidos democráticamente por los ciudadanos en 1932, en el contexto de la autonomía política conseguida por Catalunya durante la Seguna República española. A partir de febrer de 1939, las dependencias del Parlament - con el hemiciclo como punto central - fueron cerradas y tapiadas y la planta baja quedó para exhibición de las colecciones de pintura del llamado Museo de Arte Moderno.

Si el cambio de denominación era un indicador humillante, el otro gran elemento de impacto fue la ornamentación de la fachada: tres enormes esvásticas, acompañadas de dos banderas «nacionales» cubrían la fachada principal del edificio. Posiblemente, 
la combinación de estos elementos - el cambio de denominación oficial, las banderas en la fachada, más los contenidos de la exposición - fue uno de los éxitos más notables del franquismo en su programa de manipulación histórica y reescritura del pasado reciente.

La primera toma de contacto con la Exposición se produjo el 19 de octubre, cuando los responsables de la muestra invitaron a un selecto grupo de periodistas y autoridades franquistas a visitarla antes de abrir las puertas al público ${ }^{29}$. Según la crónica publicada, la delegación invitada era de primer nivel:

\begin{abstract}
Asistieron el teniente de alcalde señor Azcoitia, en representación del Ayuntamiento; el secretario de la Jefatura Provincial de Prensa, señor Bernabé Oliva $^{30}$, y el presidente de la Asociación de la Prensa, señor Ramírez Pastor, así como representantes de todos los periódicos y agencias informativas de nuestra ciudad. Hicieron los honores a los invitados el vicecónsul de Alemania, señor Reuschenbach; el doctor Hettlage, representante del profesor Albert Speer, ministro del Reich, organizador del certamen y autor de numerosas obras de las que en él se exhiben; el doctor Biebrand, consejero de aquel ministro; el comisario de la Exposición, señor Otto Renner; don Heriberto Giors, de los Ferrocarriles Alemanes, y don Oscar Streit, representante de la D.N.B.
\end{abstract}

La presencia de los periodistas, en una convocatoria previa a la inauguración oficial, tenía una utilidad que iba más allá de la estrictamente informativa. En los primeros años de la dictadura franquista, los periodistas - y los medios para los que trabajabanasumían la función de «intelectuales orgánicos» del régimen. Con la intelectualidad española - y catalana - mayoritariamente diezmada por la represión y la depuración franquistas y el exilio, la dictadura convirtió la prensa en la principal herramienta de transmisión política e ideológica, en una especie de fuerza de infantería, de primera línea de combate cultural e ideológico. Por este motivo, agasajar a los periodistas no solamente era asegurarse la presencia en los medios - cosa que era inevitable, teniendo en cuenta las directrices del poder -, sino que también representaba poder explicar el

\footnotetext{
29. «Hoy será inaugurada la Exposición de Arquitectura Moderna alemana. Visita de la prensa barcelonesa», en Diario de Barcelona, 20 octubre 1942.

30. En la organización jerárquica y piramidal del franquismo, todos los directores de medios, y estos mismos medios, estaban controlados por la Delegación Provincial de Prensa, desde donde se ejercía la censura previa sobre todo lo que se publicaba o radiaba. José Bernabé Oliva, de militancia carlista y colaborador en buena parte de la prensa de Barcelona, era el máximo responsable del aparato político de censura y control en la provincia. Cfr. FABRE, Jaume, Periodistes uniformats: diaris barcelonins dels anys 40. La represa i la repressió, Barcelona, Col-legi de Periodistes-Diputació de Barcelona, s.a. [1996].
} 
significado profundo de la muestra a los supuestos «creadores» - o, mejor, «transmisores» - de opinión de la dictadura franquista.

¿Qué ofrecía la Exposición? En palabras del vicecónsul Reuschenbach, mostraba «una breve impresión de la nueva orientación arquitectónica alemana. [...] No se pretende [...] imponer la orientación artística alemana a otros pueblos, ya que el alemán siente una gran admiración por los inmortales monumentos de la arquitectura española»31. El vicecónsul pedía a la prensa barcelonesa su ayuda «para que sus lectores aporten su simpatía y su comprensión por el modo alemán de apreciar las cosas»32. Pero más allá de las palabras protocolarias del diplomático, la Exposición reclamaba un análisis más pausado, tanto de quien la había inspirado - Albert Speer -, como del significado de las obras cuyos proyectos, maquetas, dibujos, etc., iban a ser mostrados. Y un buen ejemplo de este análisis lo ofrecía uno de los grandes periódicos de la ciudad 33 :

La Exposición de Arquitectura Alemana Moderna, que se inaugurará hoy en el Palacio de Arte Moderno de la Ciudadela, y se celebrará hasta el día 4 de noviembre, ha sido organizada bajo la alta dirección del señor Albert Speer, ministro del Reich e inspector general de Edificación de la ciudad de Berlín.

Es la personalidad de Albert Speer una de las más relevantes en el campo de la actual arquitectura alemana. Nacido en Manheim en 1905, cursó estudios en la Alta Escuela Técnica de Berlín. En posesión de las carreras de ingeniero y arquitecto, prestó relevantes servicios en el período de organización del nuevo Estado Nacional Socialista, distinguiéndose con la construcción de las grandes obras destinadas a los congresos y reuniones del partido de Nuremberg. En 1937 fue nombrado inspector general de Edificación de la ciudad de Berlín, y en esta calidad encargado de los grandes planes de reforma que vieron un comienzo de realización y de los que son elementos destacados el magnífico edificio de la nueva Cancillería y la larga avenida transversal que cruza Berlín de este a oeste, con toda una serie de importantes edificios. La labor desarrollada en este aspecto indujo al Führer, a raíz de la desgracia que costara la vida al doctor Todt, a confiar el Ministerio, por éste antes regentado, a Albert Speer, que figura entre los colaboradores más íntimos de Adolf Hitler. Con ello vino a sumarse a sus ya importantes tareas, de magnitud histórica, una misión de la mayor trascendencia. A ésta se debe que el señor Speer

\footnotetext{
31. Diario de Barcelona, 20 octubre 1942.

32. «Exposición de Arquitectura Moderna alemana. Visita preliminar de la Prensa de Barcelona», en La Vanguardia Española, 20 octubre 1942.

33. «Exposición de Arquitectura Moderna alemana. Autores, concepción y sentido de la nueva arquitectura alemana», en La Vanguardia Española, 20 octubre 1942.
} 
no haya podido asistir personalmente a la inauguración de la Exposición que con tanto cariño ha organizado.

La primera gran obra arquitectónica en un ambiente histórico y urbano fue la Plaza Real de Munich, debida al primer arquitecto del Führer, Paul Ludwig Troost, fallecido, por desgracia, poco antes de terminarla. A ambos lados de los Templos de la Fama, erigidos en conmemoración de los muertos del intento de alzamiento nacional de noviembre de 1923, dos grandes edificios de la Jefatura Suprema del Movimiento cierran la parte oeste de la plaza, que, despojada de todo elemento natural y fortuito (como árboles y verdor), da un marco de piedra severo y digno a los héroes caídos. Fue también Troost autor de la nueva Casa del Arte Alemán, en la que se celebran exposiciones anuales de pintores alemanes contemporáneos y que reafirman la posición de Munich como importante centro de actividad artística.

En Nuremberg, la ciudad de los congresos del Partido Nacional Socialista, es donde puede comprobarse mejor el influjo, antes señalado, de la renovación política sobre las creaciones arquitectónicas: aquí, en efecto, surgió en la mente del Führer, al calor de las primeras y cada vez mayores manifestaciones al aire libre, el magno proyecto de la Explanada de los Congresos del Partido, conjunto de construcciones monumentales de las que algunas estaban casi terminadas ya al interrumpirse las obras a consecuencia de la guerra los edificios del Foro del Movimiento, el Pabellón del Congreso, la amplia Vía de los Desfiles, de 90 metros de anchura; el Campo de Marzo, que servirá en el futuro para las manifestaciones del Ejército; el "Zeppelinfeld", el proyectado Estadio Alemán, son sus partes esenciales. El planteamiento fue encomendado en 1934 a Albert Speer, el cual concibió un eje atrevido en el dispositivo general y amplió considerablemente las proporciones totales de éste, que fue, además, puesto en contacto más estrecho con la vieja ciudad.

Pero la cima y remate de las reformas urbanas habrá de ser la de Berlín, encomendada también a Speer, según hemos indicado, ya en 1937, y para la cual se han destinado fondos extraordinarios. Se prevé una gran cruz de calles con eje dominante Norte-Sur, con cuatro grandes calles de circunvalación destinadas a descongestionar el tráfico interior, y nuevos espacios de verdor que penetrarán profundamente como lenguas radiales en el antiguo núcleo urbano. Ya en 1939 se había terminado una parte importante de la avenida Este-Oeste desde la Puerta de Brandenburgo hasta la Plaza de Mussolini. Poco antes se había construido también el primer edificio representativo dentro de la reforma: la Nueva Cancillería. Ésta, elevada por Speer en el breve espacio de nueve meses, presta su marco adecuado a las esculturas de Arno Breker, a los mosaicos de Herman Kaspar y a los gobelinos de Werner Peiner, y es tan característica del nuevo espíritu por sus líneas externas, 
equilibradas y sencillas, como por su aspecto interior, en el que sobresalen la gran galería de mármol y el despacho del Führer.

Otra serie de ciudades serán también objeto de amplias reformas. Entre los nombres de arquitectos destacados, podemos añadir a los de Troost y Speer, los de Joseph Thorak y Kurt Schmid-Ehren, que han actuado en Munich y Nuremberg; Hermann Giesler, Roderich Fink y Wilhelm Kreis, cuya labor ha sido, asimismo, muy fecunda y variada.

Hagamos, finalmente, una breve referencia a las Escuelas de Mandos, entre las que cabe citar la de Sonthofen, obra de Giesler; numerosos Hogares de la Juventud Hitleriana; la Escuela Superior del Partido, que ha comenzado a construirse en Chiemsee, etc. Muchas de estas obras no han podido terminarse aún por causa de la guerra, pero por deseo expreso del Führer la labor de planeamiento prosigue a pesar del conflicto sentando las bases de la futura actividad constructiva.

Podían hacerse lecturas más amplias del significado general de la Exposición. Así lo creía un crítico de arte falangista, Luis Monreal Tejada34, quien, como hicieran anteriormente Manuel Brunet o Manuel Penella de Silva, también se dejaba llevar por el fascinante poderío nazi: «La Exposición de la Moderna Arquitectura Alemana, en estos momentos de lucha en defensa de una Civilización milenaria, constituye un símbolo y una realidad. Reafirma la existencia del espíritu europeo y demuestra que éste posee en nuestro tiempo tanta vitalidad como en otras épocas históricas de las que nos sentimos orgullosos. Y esta conclusión, clara y manifiesta, debe llenarnos de confianza en los destinos de nuestro Occidente»35. Previamente, se había referido «a la presentación maravillosa de esta Exposición», «muestra de lo que el impulso hitleriano logra, servido por la disciplina y el trabajo de su pueblo». Después venía la referencia inexcusable al monasterio de San Lorenzo del Escorial, como ejemplo de que también en España había existido una arquitectura con ambiciones imperiales; y se adentraba en la propuesta «neoclásica» de la nueva arquitectura alemana: «El Neoclásico

34. Luis Monreal Tejada era, en aquellos años, responsable del servicio de recuperación de objetos de arte en Cataluña y Valencia, un organismo del Ejército franquista responsable de recuperar y reorganizar el patrimonio artístico afectado por los tres años de guerra que había permanecido, hasta el final del conflicto, en manos de las autoridades republicanas. Instalado en Barcelona, Monreal Tejada colaboraba asiduamente en el periódico falangista Solidaridad Nacional y, con los años, se convirtió en uno de los mejores y más representativos representantes de la buena sociedad franquista barcelonesa. Mediante sus peripecies personales y profesionales, el historiador puede hacerse una buena idea de las ventajas y privilegios de que gozaron los vencedores de la guerra a lo largo de la dictadura. Cfr. un amable e indulgente retrato del personaje en Sergio Vilasanjuán, «Tertulias, cenas y conciertos: un diario cultural de posguerra», en La Vanguardia, 7 junio 2002.

35. CALISTENES [MONREAL TEJADA, Luis], «Una nueva interpretación del Clasicismo», en Solidaridad Nacional, 21 octubre 1942. 
hitleriano es de máxima sobriedad. Puede decirse que posee un rigor filosófico en la simple composición de líneas y masas. Triunfa la línea recta, a la que con gran oportunidad y mesura se la yuxtapone al sereno contraste del medio punto o el ritmo subyugador de la columnata. Algunas veces unos relieves o unas estatuas animan el conjunto arquitectónico. Pero es éste siempre el que se impone y triunfa como símbolo del pensamiento constructor de los capitanes de la nueva Europa». Maquetas, proyectos, fotografías, etc., «son asombro del visitante», todo era admirable. Alemania y su arquitectura tenían amigos incondicionales y rendidos en Barcelona.

El martes, 20 de octubre, se llevó a cabo la inauguración. La representación política y social del poder franquista fue de primer orden: «El acto lo presidieron el Capitán General del IV Región, teniente general Kindelán; el Gobernador civil y Jefe provincial del Movimiento, don Antonio de Correa; el embajador de Alemania en España, señor Stohrer; el Gobernador militar, general Moreno Calderón; alcalde accidental de Barcelona, señor Joaniquet; vicepresidente de la Diputación Provincial, señor Batlló; rector de la Universidad y Delegado provincial de Educación Nacional, señor Gómez del Campillo; canónigo doctor Faura, por el obispado, figurando también entre los asistentes al acto el Jefe Superior de Policía, coronel Asensi Cepero...»36. Además de los máximos representantes del poder político - provincial y local -, militar y policial, el «nuevo» estamento académico e intelectual - los hombres que habían ocupado los puestos vacantes en la universidad, las instituciones culturales y científicas, etc., tras la represión y la depuración franquistas - también hizo acto de presencia: Luis Monreal Tejada, «comisario de la Defensa del Patrimonio Artístico Nacional» y pieza clave en el mercado de arte barcelonés; Luis Moragas, del Sindicato Español Universitario (S.E.U.); Javier de Salas, director del llamado Museo de Bellas Artes y profesor en la universidad de Barcelona; Martín Almagro, catedrático de Prehistoria y director del Museo Arqueológico;37 Buenaventura Bassegoda, catedrático de la Escuela de Arquitectura, que tendría un activo papel en relación a la Exposición; etc. Era, pues, un acontecimiento que provocó una mobilización social de gran envergadura. La Barcelona franquista había entendido que se encontraba ante una ocasión excepcional y así lo manifestó asistiendo a la inauguración en el mal llamado Palacio de Arte Moderno.

\footnotetext{
36. «La Exposición de Arquitectura Moderna alemana. Fue inaugurada ayer solemnemente, presidiendo el acto el Embajador de Alemania en España y nuestras primeras autoridades», en Diario de Barcelona, 21 octubre 1942.

37. En las conexiones políticas, científicas, académicas, etc., entre la dictadura franquista y Alemania, la trayectoria - y su presencia en la inauguración de la Exposición así lo demuestra de Martín Almagro ofrece un perfil muy singular. Cfr. GRACIA ALONSO, Francisco, La arqueología durante el primer franquismo (1936-1958), Barcelona, Bellaterra, 2009, especialmente el capítulo 6: La relación entre los arqueólogos españoles y la Alemania nazi.
} 
Por parte alemana, la representación también era de alto nivel. Al embajador en España, le acompañaban «el profesor Huttlage, que representaba al ministro, señor Speer; el Consejero ministerial, doctor Biebrach, que ostentaba la representación del ministro alemán de Propaganda, Dr. Goebbels; el cónsul general de Alemania, doctor Jaeger; los vicecónsules señores Reuschembach, conde Strachwitz y Ruggenberg; el jefe del Partido Nacionalsocialista en Barcelona, señor Knopff; el jefe de dicho partido en España, Sr. Thimmann y otras jerarquías del mismo y representantes de las diversas entidades culturales y económicas de Alemania en nuestra ciudad». La confluencia, en un mismo espacio, de cuadros oficiales falangistas y nazis, dirigentes y responsables políticos y militares españoles y alemanes, era una magnífica imagen de la falsa neutralidad española ante el conflicto europeo y reafirmaba las amistosas relaciones entre las dos dictaduras.

Abrió el acto el vicecónsul alemán en Barcelona, quien se reafirmó en el tópico de la vinculación especial entre la arquitectura «y la persona del Führer y de su voluntad constructiva [...] que con el mayor relieve traduce el carácter del Nacionalsocialismo». ${ }^{8}$ Después, el doctor Hettlage ofreció un discurso de mayor contenido e intención: «Realzó la importancia que en todo tiempo ha tenido la arquitectura como manifestación más inmediata y duradera de la historia de una nación»; también explicó que una construcción «frecuentemente ofrece más indicaciones sobre los hechos de un siglo entero, que un millón de documentos impresos», e hizo una afirmación que, naturalmente, la realidad diaria desmentía: «Alemania no tiene el deseo de implantar su modo de ser y su concepto artístico a otrs pueblos extranjeros por los que siente la misma estimación».

Por parte franquista, la bienvenida fue a cargo del alcalde accidental, Aurelio Joaniquet, un veterano político de la extrema derecha monárquica, bien aposentado en el franquismo y recién llegado, como tantos otros, al falangismo. Era un bun representante del stablishment político y social de la Barcelona franquista y su imagen de severidad burguesa y conservadora ilustraba perfectamente el maridaje entre derechas tradicionales y fascismos de nuevo cuño. Su papel en el evento no debía

38. Para ser más precisos, el cónsul Jaeger había manifestado: «Por ahora, permitidme llamar, con toda insistencia, la atención sobre el hecho de las construcciones de Adolfo Hitler y todos sus proyectos en este terreno deben ser considerados como un documento de los inquebrantables ideales de paz del pueblo alemán. Adolfo Hitler, cuya voluntad se concentra en forma tan intensiva sobre la constrrucción de obras de paz [...] había deseado de todo corazón la paz para su pueblo, para poder dar forma a estas monumentales construcciones de arte y realizarlas, pues solamente la paz garantiza la libre continuación y feliz terminación de tales obras. Esta paz, fuerte y victoriosa, llegará un día a ser una realidad, y será también la señal y precondición para dar principio a una empresa gigantesca y para su solución» (en Solidaridad Nacional, 21 octubre 1942). 
limitarse a dar la bienvenida a la delegación alemana, sino que también debía reivindicar los méritos españoles:

\begin{abstract}
Nos traeis, señores, esta manifestación de la moderna arquitectura alemana, en momentos en que nuestro ánimo está bien dispuesto para recibirla y comprenderla. No está lejano el día en que España luchaba contra el comunismo ruso en su propio suelo, y en aquel primer acto de la gran tragedia europea, el gesto de Alemania y de Italia no fue de indiferencia sino de hospitalidad para las familias evadidas de su hogar y de ayuda para vencer al enemigo común que trataba de establecer un punto de apoyo en el occidente de Europa para sojuzgarla después más fácilmente.

Por ello, en justa correspondencia, nuestra División Azul, formada por voluntarios pertenecientes a todas las clases sociales, acompaña a los soldados alemanes en los campos de Rusia, en la heroica lucha contra el comunismo. España no espera impasible que derrameis vuestra sangre en beneficio de todos, sin hacer ninguna aportación. [...] la España de hoy, que tiene por lema el que la vida del hombre sobre la tierra es milicia, es partícipe de la dura Cruzada contra el comunismo, porque sabe que sin su destrucción previa no puede haber fortuna, ni dicha, ni religión, ni moral, ni paz entre los hombres.
\end{abstract}

Ciertamente, el discurso inaugural del alcalde accidental de Barcelona tenía poco que ver con los contenidos de la Exposición, su significación, etc. Pero era previsible que fuera así; el franquismo, en todos sus niveles, padecía de un sentimiento de inferioridad y envidia ante el desplegamiento del poder nazi en Europa, que obligaba a sus cabezas visibles - militares, civiles, intelectuales, propagandísticas, etc. - a insistir una y otra vez en la «España precursora y victoriosa» en el combate universal contra el comunismo, como una fórmula para reivindicar un supuesto poderío español y, sobre todo, evitar el relegamiento de la dictadura española al furgón de cola de las nuevas potencias fascistas europeas. De aquí que Aurelio Joaniquet trajese a colación la victoria de 1939, la División Azul y otros supuestos méritos, que permitiesen equilibrar la percepción de inferioridad ante la exhibición de obras arquitectónicas alemanas. Probablemente, la delegación nazi presente en el Palacio de Arte Moderno asintió con amabilidad y corrección al discurso, pero se ciñó a la misión que se le había encomendado: fascinar a Europa con los grandes proyectos urbanísticos y arquitectónicos que definían, mejor que muchos discursos, el renacido poder alemán más allá de sus fronteras.

Reafirmada, por parte del alcalde accidental, la indestructible alianza de amistad entre los dos países, aun tuvo tiempo para evocar la «españolización» de algunos 
artistas alemanes y citar el nombre de académicos contemporáneos, como Karl Vossler, «que han sabido comprender el espíritu español y han aportado al estudio y conocimiento de las cosas de España su preclara inteligencia».

Desde este momento, y hasta el 4 de noviembre, la Exposición quedó abierta al público. Rápidamente, se organizaron visitas colectivas de diferentes grupos de la ciudad. Algunos institutos de enseñanza media mandaron a sus alumnos, caso de los centros Menéndez Pelayo y Maragall; también hicieron acto de presencia un grupo de militares del Centro Cultural del Ejército y de la Armada; y el Frente de Juventudes -la organización juvenil falangista - mandó una delegación el mismo día que visitaron la Exposición los alumnos del Instituto del Teatro39. Les seguirían los alumnos de la Escuela de Ingenieros Industriales, del Colegio Alemán (28 de octubre) y profesores y alumnos de la Escuela de Arquitectura, encabezados por el secretario y catedrático Buenaventura Bassegoda, quien iba acompañado de Emilio Canosa, decano de la Escuela Superior de Arquitectura de Madrid. Este grupo de visitantes, así como más tarde «los círculos intelectuales y autoridades de nuestra ciudad», gozaron de la oportunidad de visionar las películas Arquitectura en la Alemania de Adolfo Hitler y Expresión en piedra ${ }^{40}$.

El 4 de noviembre se clausuraba la Exposición. Antes de cerrar puertas, aun la visitaron miembros del «Departamento de Aparejadores del S.E.U.» y de la Escuela Superior de Bellas Artes. Con ellos, la muestra había llegado a los 30.000 visitantes, una cifra muy notable para una actividad de estas características y en una ciudad que vivía castigada por una muy dura posguerra.

\section{Una última reflexión de un especialista: Buenaventura Bassegoda}

Muy probablemente, la prensa barcelonesa se expresaba con toda sinceridad cuando calificaba la Exposición de éxito. Miles de visitantes, proyecciones de documentales, movilización de las organizaciones falangistas y de los centros educativos, etc., era un buen balance de la muestra y su impacto.

Pero también en los ambientes más intelectuales y especializados había recibido una notable atención. Manuel Brunet había dedicado un extenso comentario al librocatálogo -además de sus análisis sobre la arquitectura fascista -; Luis Monreal se

39. Cfr. La Vanguardia Española (31 octubre 1942) y Diario de Barcelona (27 y 30 octubre 1942).

40. "Sesión de cine en la Exposición de "Arquitectura Moderna alemana"», en Diario de Barcelona, 30 octubre 1942. 
declaraba rendido al poderío nazi. $\mathrm{Y}$ el catedrático y «secretario perpetuo» de la Escuela de Arquitectura de Barcelona, Buenaventura Bassegoda, que había sido visitante asiduo de la Exposición, también le dedicó una atención especial. En aquellos tiempos de posguerra, Bassegoda era uno de los arquitectos de referencia del franquismo local. Formado en lops ambientes conservadores y católicos de preguerra, a partir de 1939 fue uno de los referentes académicos e intelectuales de los proyectos de restauración de edificios - sobre todo religiosos - destruidos o castigados por la guerra y la revolución, y tuvo un papel muy activo en los círculos culturales de la buena sociedad franquista. Tanto se le podía encontrar en el Círculo Cultural del Ejército y de la Armada, explicando al personal militar las destrucciones de que fue víctima la basílica gótica de Santa Maria del Mar por parte de la «horda roja», como era delegado por el ayuntamiento de Barcelona para representarlo en el congreso internacional de arquitectura, convocado en Berlín en noviembre de 1942.

Muy activo más allá de su cátedra universitaria, era lógico que mostrara y manifestara su interés especial por la Exposición de Arquitectura Moderna alemana. Desde las páginas del semanario Destino. Política de Unidad (la revista políticocultural más importante de la España de posguerra), el arquitecto pudo manifestar su satisfacción porque el público barcelonés, «hipersensible ante toda manifestación de nuda arquitectura, acostumbrado a buscar la virtud en el comedio, sin caer en el defecto de comiar lo mediocre y lo trivial», había expresado su gran admiración por la «nueva arquitectura alemana»41. Pero más allá de la reacción ciudadana, ¿qué era lo realmente relevante? Por ejemplo, según el arquitecto Bassegoda: «La unánime voluntad de victoria de un pueblo queda aquí de manifiesto en perfecta equipolencia con el triunfo de los nuevos cánones morfológicos. Recordemos. Luego de una importante aportación, claramente antinacional, del grupo judío, que alcanzó éxitos indiscutibles como Gropius i Mendelssohn, mientras los estadistas republicanos, en el sanedrín del Leman, se adormilaban arrullados por la voz del violoncelo de Briand, el pueblo alemán reconoce en Adolfo Hitler al hombre extraordinario llamado a levantarlo del oprobio en que vivía por las malas artes de sus enemigos. Y la revolución nacional-socialista, que sacude el organismo estatal desde el zampeado hasta el fastigio, ha de remover también el universo plástico, para orientarlo hacia metas más limpias y excelsas. Ahitos de alabar, sin entenderlo, el arte cerebral, abstracto, árido y convencional, que se empeña en colocar la nariz o la rodilla en el lugar del ombligo, vemos con alivio que la arquitectura hitleriana propugna un nuevo clasicismo...».

41. BASSEGODA, Buenaventura, «La nueva arquitectura alemana», in Destino. Política de Unidad, 276, 31 octubre 1942. 
«Aliviado» por haber podido superar la «arquitectura judía» y «el arte cerebral», Bassegoda se expresaba con gran contundencia:

La reacción artística, verdaderamente gigantesca, que representa la instauración del nuevo régimen, habla directamente al alma del pueblo alemán con el lenguaje, para él más halagüeño, de una arquitectura imponente por su importancia y dimensión y en la que el valor prócer y eterno de la cantería hácese símbolo de la firmeza del ideal político representado. A los admiradores de la Bauhaus, esta deliberada arquitectura de Estado puede antojárseles regresión a un adocenado renacimiento clásico.

Pero el observador imparcial comprende en seguida que está inspirada por una visión más amplia y grandiosa y menos personal y rebuscada que la que animara la correcta sobriedad prusiana de Schinkel, la serena gracia italiana de Lukae y de Semper o el recio empuje paladiano de Hoffmann. Nos hallamos en presencia de una voluntad de afirmación, de un afán de orden y de disciplina que sólo halla fidelidad hermenéutica en solemnes y colosales obras arquitectónicas. Lo dijo Giesler: «Cogemos el pico y la bujarda porque el pincel y los colores nos parecen harto menguados para representar esta época heroica. Asentamos a hueso un sillar sobre otro para lograr una obra en la que cada unidad está tan próxima a las contiguas como nuestras manos en la hermandad y nuestros corazones en la fe.

Rendido, como tantos otros franquistas, ante el deslumbramiento alemán, Buenaventura Bassegoda terminaba invocando el «milagro arquitectónico que estos días nos asombra», producto del «triunfo de la revolución nacional bajo la guía señera de Adolfo Hitler».

Ciertamente, tenía que hablarse de «asombro», fascinación, admiración. La Alemania nazi, en mayor medida que la Italia fascista, era una referencia inexcusable para la Barcelona franquista y el conjunto del sistema dictatorial español. Ideológicamente, culturalmente, en su organización política y supuesta eficiencia administrativa y de gestión, en su supuesto sentido de la renovación histórica (todo, en la Alemania nazi, era nuevo: la nueva arquitectura, el nuevo orden, la nueva Europa...), etc., la dictadura alemana era un modelo admirable, el summum de lo nuevo que vendría tras barrer los restos de la decadente sociedad burguesa y liberal del siglo XIX y las primeras décadas del Xx. En cierta forma, Aurelio Joaniquet lo había sintetizado en su discurso inaugural: "puestas en contacto las creaciones de vuestra moderna arquitectura con la fuerte y robusta personalidad hispánica, se originen formas nuevas, rindiendo en definitiva culto a la belleza y al progreso humano, patrimonio de todos los 
pueblos». Naturalmente, nadie en la Barcelona franquista se preguntaba por el alto precio a pagar por las «formas nuevas» o la dirección que tomaría el «progreso humano» prometido por la Alemania hitleriana. 


\section{* El autor}

Francesc Vilanova i Vila-Abadal (Barcelona, 1962) es Profesor Titular de Historia Contemporánea en la Universidad Autónoma de Barcelona y Director del Archivo Carles Pi i Sunyer (Fundació Carles Pi i Sunyer d'Estudis Autonòmics i Locals, Barcelon). Miembro del Grup de Recerca en l'Època Franquista (GREF) y del Centre d'Estudis sobre les Èpoques Franquista i Democràtica (UAB-CEFID). Sus últimos trabajos publicados son: La Barcelona franquista i l'Europa totalitària (1939-1946) (Barcelona, Editorial Empúries, 2005); El franquismo en guerra. De la destrucción de Checoslovaquia a la batalla de Stalingrado (Barcelona, Península, 2005), Exiliats, proscrits, deportats (Barcelona, Editorial Empúries, 2006), 1939 (Barcelona, Península, 2007), Una burgesia sense ànima. El franquisme i la traïció catalana (Barcelona, Editorial Empúries, 2010), L’any que va caure París. Aliadòfils $i$ franquistes catalans l'estiu de 1940 (Barcelona, La Magrana, 2010).

URL: < http://www.studistorici.com/progett/autori/\#Vilanova_Vila-Abadal >

\section{Per citare questo articolo:}

VILANOVA i VILA-ABADAL, Francesc, «Bajo el signo de la esvástica. La Exposición de Arquitectura Moderna alemana en España (1942)», Diacronie. Studi di Storia Contemporanea : Le esposizioni: propaganda e costruzione identitaria, 29/6/2014,

URL: < http://www.studistorici.com/2014/06/29/vilanova_vila-abadal_numero_18/ >

Diacronie Studi di Storia Contemporanea $\beta$ www.diacronie.it

Risorsa digitale indipendente a carattere storiografico. Uscita trimestrale.

redazione.diacronie@hotmail.it

Comitato di redazione: Jacopo Bassi - Luca Bufarale - Elisa Grandi - Deborah Paci - Fausto Pietrancosta - Matteo Tomasoni - Luca Zuccolo 